\title{
Phenotypic plasticity in Crepis tectorum (Asteraceae): genetic correlations across light regimens
}

\author{
STEFAN ANDERSSON* \& RUTH G. SHAW $\dagger$ \\ *Department of Systematic Botany, University of Lund, Ö. Vallgatan 18-20, S-223 61 Lund, Sweden and TDepartment \\ of Ecology, Evolution and Behaviour, 100 Ecology Building, 1987 Upper Buford Circle, University of Minneapolis/St. \\ Paul, St. Paul, MN 55108, USA
}

\begin{abstract}
Inbred $\mathrm{F}_{3}$ and $\mathrm{F}_{4}$ families from a cross between two contrasting ecotypes of Crepis tectorum were replicated in two regimes in a glasshouse to determine whether genetic tradeoffs within the reaction norm favour genetic differentiation over phenotypic plasticity in this species. There was no tradeoff in reproductive fitness (flower production) across light regimes but genetic cross-environment correlations approached unity for a wide range of characters subject to divergent selection across habitats, suggesting little genetic variation in plasticity and a limited opportunity for selection to favour broadly adapted genotypes capable of attaining the optimum phenotype in every environment. The presence of genotype-environment interaction without large changes in the ranking of genotypes over light regimes indicates a greater potential for evolutionary change in environmental sensitivity although developmental constraints may limit the range of phenotypes that can be expressed in a character. A selection analysis was conducted to determine how the average reaction norm would evolve in this system. Whereas the relationship between each trait and reproductive fitness was environment-specific, there was no change in the direction of selection between light regimes. Given the genetic correlation structure observed, one would expect some of the genetic response in one environment to carry over to the other environment.
\end{abstract}

Keywords: Genotype-environment interaction, phenotypic plasticity, reaction norm, tradeoffs.

\section{Introduction}

The reaction norm, defined as the range of phenotypes that can be produced by a genotype in response to a specific range of environmental conditions (Schmalhausen, 1949), has become a major focus of empirical and theoretical studies of organisms in spatially or temporally variable habitats (Via \& Lande, 1985; Schlichting, 1986; Sultan, 1987; Stearns, 1989; van Tienderen, 1991; Gabriel \& Lynch, 1992; Gomulkiewicz \& Kirkpatrick, 1992), particularly since the influential review of Bradshaw (1965), who emphasized the adaptive role of phenotypic plasticity. A reaction norm can evolve by natural selection when there is heritable variation in phenotypic response, when the optimum phenotype differs between habitats and when the scale of spatial heterogeneity is small relative to the mean distance of gene flow (Bradshaw, 1965; Via \& Lande, 1985). Comparative studies of species or conspecific

\footnotetext{
${ }^{*}$ Correspondence.
}

populations derived from different habitats and grown across the same set of environments support the notion that plasticity can be moulded by selection, both in plants and animals (e.g. Björkman \& Holmgren, 1963; Cook \& Johnson, 1968; Hickman, 1975; Khan \& Bradshaw, 1976; Zimmerman, 1976; Mooney, 1980; Newman, 1988; Conover et al., 1992) but there is still little consensus as to whether selection acts on plasticity per se (e.g. Scheiner \& Lyman, 1989b) or whether the reaction norm evolves indirectly through selection on phenotypes expressed in distinct environments (e.g. Via \& Lande, 1985; Falconer, 1990).

While numerous techniques have been employed to document heritable differences in the reaction norm (Schlichting. 1986; Scheiner \& Lyman, 1989a), there have been few attempts to determine the genetic basis of phenotypic plasticity in a form that allows specific predictions of the response of a population experiencing selection at the phenotypic level. A recent model that describes the evolution of plasticity (Via \& Lande, 1985) employs the term $r_{G}$, the genetic correlation 
between the same trait measured in two distinct environments (Falconer, 1952). In this approach, different character states are regarded as (potentially) genetically correlated through the expression of the same alleles in different environments and no attempt is made to collapse the reaction norm into such statistics as the overall mean and the amount of response (cf. Lacey et al., 1983; Scheiner \& Lyman, 1989b; Schlichting \& Levin, 1990; Weis \& Gorman, 1990). Along with measurements of selection within each environment (Lande \& Arnold, 1983) and the frequency with which each environment is encountered by the population, estimates of $r_{\mathrm{G}}$ can be used to predict how phenotypic plasticity will evolve in different systems, to determine whether local selection would promote genetic specialization to particular environments and to examine whether genotype by environment interaction contributes to the maintenance of additive genetic variation within a population.

Unfavourable genetic correlations between character states can constrain the evolution of phenotypic plasticity (Via \& Lande, 1985) but so far few studies have documented genetically based tradeoffs within the reaction norm (Fry, 1990; Via, 1991). Although such tradeoffs may indeed be rare, it must be emphasized that the estimation of $r_{\mathrm{G}}$ is fraught with severe statistical problems; product-moment correlations of family means are easy to calculate but include fractions of the within-family variance, while (unbiased) estimates of $r_{\mathrm{G}}$ based on genetic components of (co)variance cannot be statistically tested by the usual approaches (Via, 1984b). Under certain assumptions, two-way analysis of variance provides a simple test of the hypothesis that $r_{\mathrm{G}}$ differs from zero (Fry, 1992) although maximum-likelihood techniques may be more suitable when data are highly unbalanced (Platenkamp $\&$ Shaw, 1992). Both approaches avoid the necessity of using the family-mean correlation as a simple but (potentially) biased measure of $r_{\mathrm{G}}$.

Whether genetic correlations across environments translate into a constraint that prevents an organism from responding optimally depends on the direction of selection in each environment. To date, most workers have searched for negative values of $r_{\mathrm{G}}$ for traits with positive effects on fitness irrespective of growth conditions (Via, 1984b, 1991; Shaw, 1986; Futuyma \& Moreno, 1988; Miller and Schemske, 1990; Shaw \& Platenkamp, 1993) whereas few efforts have been made to quantify $r_{\mathrm{G}}$ for characters that might be subject to disruptive selection across environments (but see Platenkamp \& Shaw, 1992). When the direction of selection differs between habitats, one would expect a value of $r_{G}$ close to one to represent a constraint on reaction norm evolution (Via \& Lande, 1985).
Present-day populations may be genetically fixed due to genetic drift or past episodes of selection (Falconer, 1981). Segregating progenies from crosses between differentiated populations display expanded variation and therefore offer an enhanced opportunity to determine the heritable basis of differences in specific traits (Mather \& Jinks, 1982), including their phenotypic plasticity (Khan et al., 1976) and also improve the precision with which $r_{\mathrm{G}}$ can be estimated; only heritable traits can be genetically correlated. Selfed families representing the $\mathrm{F}_{3}$ or later generations are particularly useful, as related individuals can be replicated across the same set of environments.

Previous work on the plant Crepis tectorum has revealed adaptive differentiation in a wide range of characters, particularly in relation to drought and light intensity (Andersson, 1989a-c, 1990, 1991, 1993) but little is known about the factor(s) that favour ecotypic differentiation over wide phenotypic plasticity in this taxon. Using inbred $\mathrm{F}_{3}$ and $\mathrm{F}_{4}$ progenies derived from a cross between two distinct ecotypes and grown across two light regimens, we quantified $r_{\mathrm{G}}$ for a wide range of vegetative and reproductive characters to determine whether genetic tradeoffs within the reaction norm would constrain the evolution of plasticity as an alternative means of adapting to the wide variety of habitats occupied by Crepis tectorum. Attempts were also made to predict how the average reaction norm would evolve in the glasshouse environment, given the genetic correlation structure and the pattern of phenotypic selection in the two light regimens.

\section{Materials and methods}

The diploid Crepis tectorum L. (Asteraceae) flowers between May and September when the leaf rosette develops a single stem that may have various numbers of heads, each of which contains up to 100 flowers. Each fertilized flower develops into a one-seeded indehiscent fruit dispersed by the wind (termed 'seeds' in this paper). In addition to a weed taxon which occurs in a wide range of ruderal and agrestal habitats throughout the range of the species, there are at least four genetically distinct forms found in areas with exposed bedrock, three of which are confined to the Baltic lowland region (Andersson, 1990). The pattern of differentiation has developed without the origin of strong crossing barriers, facilitating genetic analyses of character evolution in this species.

In 1990, plants from a weed population in western Europe (Bordeaux, France) and an outcrop population near the village of Filehajdar on the Baltic island of Gotland (SE Sweden) were hybridized. Following a genetic analysis of a large $F_{2}$ family derived from a 
single $F_{1}$ hybrid (Andersson, 1993) and raised under uniform greenhouse conditions (University of Lund, Sweden), one of us (S.A.) established a large number of inbred $\mathrm{F}_{3}$ families by collecting selfed seeds from individual $\mathrm{F}_{2}$ plants.

On 9 June 1992, seeds from 50 randomly selected $\mathrm{F}_{3}$ families were sown on moist filter paper in petri dishes. Newly-germinated seedlings from 34 of these families and the two parent populations were planted in pots with standard soil (UC mix III) and placed in a randomized pattern in an air-conditioned glasshouse (University of California, Riverside) divided into six blocks, each having one part exposed to full sunshine and one part covered by a 50 per cent shade cloth, an environmental difference that spans or exceeds the range of light intensities encountered by most populations in nature (Andersson, unpublished data). In the following, we refer to these treatments as light regimens, even though the shade cloth also reduced water loss and air circulation.

One seedling per $\mathrm{F}_{3}$ family and four to five seedlings per parent population were represented in each of the 12 block-treatment categories, although seedling mortality and a failure to replace dead seedlings in the smallest families resulted in some losses. Most plants flowered within 3 months, enabling us to repeat parts of the study with the subsequent $\mathrm{F}_{4}$ generation. This experiment was begun on 25 August and included 39 maternal families (one seedling per family and blocktreatment combination), each of which represented the offspring of a selfed $\mathrm{F}_{3}$ plant.

Table 1 presents the characters measured on each plant as well as the transformations applied to achieve normality. Apart from measures of overall plant size and components of reproductive fitness, the data set includes vegetative and reproductive characters that differ between weed and outcrop populations and between different forms within each of these categories (Andersson, 1989a-c, 1990, 1991, 1993). Most of the $\mathrm{F}_{4}$ plants ( 71 per cent) remained in the rosette stage when both experiments were terminated $(30$ December), precluding attempts to include reproductive characters. Leaf measurements in the $F_{3}$ refer to leaves initiated just prior to flowering whereas those in the $\mathrm{F}_{4}$ are based on one pressed leaf from each plant collected 3 months after planting. Flower and seed measurements in the $F_{3}$ refer to the terminal head, while the 'branch length' refers to the third side branch from the stem apex; 'seed length' represents an average of two seeds per plant. In addition to the continuous variables, each plant was scored for the presence or absence of anthocyanin leaf spots, one of the few strictly polymorphic traits that exhibit interpopulational variation in Crepis tectorum (Andersson, 1991).

\section{Data analyses}

Leaf pigmentation was analysed with tests of independence in three-way tables in which individuals were classified according to family, light regimen and whether they had anthocyanin leaf spots (plants pooled across blocks). Continuous characters in the parent generation were analysed by three-way ANOVA using the GLM procedure in SAS (type III sum of squares; SAS, 1985) to examine the effect of block, light regimen, parent population and the interaction between population and light regimen, with all factors considered as fixed and tested over the error term. Corresponding procedures for the $F_{3}$ and $F_{4}$ generations were mixed model three-way ANOVA, with family (random) and light treatment (fixed) tested over the family by light regimen interaction, and block (fixed) tested over the error

Table 1 Characters measured in the $P, F_{3}$ and $F_{4}$ generations

\begin{tabular}{|c|c|c|}
\hline Character & Generation & Description \\
\hline Leaf length & $\mathrm{P}, \mathrm{F}_{3}, \mathrm{~F}_{4}$ & $(\mathrm{~mm})$ \\
\hline Leaf dissection & $\mathbf{P}, \mathrm{F}_{3}, \mathrm{~F}_{4}$ & Ratio of smallest to widest leaf width (In) \\
\hline Relative leaf width & $\mathrm{P}, \mathrm{F}_{3}, \mathrm{~F}_{4}$ & Ratio of leaf width to leaf length \\
\hline Relative tooth density & $\mathrm{F}_{4}$ & Ratio of tooth number of leaf length \\
\hline Leaf number & $\mathrm{P}, \mathrm{F}_{3}$ & $(\ln )$ \\
\hline Flowering date & $\mathrm{P}, \mathrm{F}_{3}$ & \# days to flowering from 1 July (ln) \\
\hline Plant height & $\mathrm{P}, \mathrm{F}_{3}$ & $(\mathrm{~mm})$ \\
\hline Branch length & $\mathrm{P}, \mathrm{F}_{3}$ & $(\mathrm{~mm} ; \ln )$ \\
\hline Head width & $\mathrm{P}, \mathrm{F}_{3}$ & $(\mathrm{~mm})$ \\
\hline Seed length & $\mathrm{P}, \mathrm{F}_{3}$ & $(\mathrm{~mm})$ \\
\hline Heads/plant & $\mathrm{P}, \mathrm{F}_{3}$ & $(\ln )$ \\
\hline Flowers/head & $\mathrm{P}, \mathrm{F}_{3}$ & $(-)$ \\
\hline
\end{tabular}

Unit of measurement and transformation shown in parenthesis. 
term. Following the estimation of the variance components attributable to family, family by light regimen interaction and within-family variation (using type III expected mean squares generated by SAs), we quantified the variance among family means within each light regimen from a separate two-way ANOVA for each trait, with family (random) and block (fixed) considered as main effects. In the absence of linkage disequilibrium, epistatic interactions and environmental sources of variation, most of the variance among $\mathrm{F}_{3}$ and $\mathrm{F}_{4}$ families can be attributed to the additive effects of genes (Mather \& Jinks, 1982; Bulmer, 1985). Seasonal variation in growth conditions (see above) precluded the separation of additive and non-additive components of variance, which would require two or more generations raised in the same environment.

We partitioned the interaction variance for each character according to the following expression (Robertson, 1959):

$\sigma_{\mathrm{GE}}^{2}=\left(\left(\sigma_{1}-\sigma_{2}\right)^{2}+\sigma_{1} \sigma_{2}\left(1-r_{\mathrm{G}}\right)\right) / 2$,

where $\sigma_{1}^{2}$ and $\sigma_{2}^{2}$ is the family variance component in two environments and $r_{\mathrm{G}}$ is the genetic correlation across environments. The term involving $r_{\mathrm{G}}$ quantifies the extent to which genotypic rankings vary between environments and was obtained as the difference between $\sigma_{\mathrm{GE}}^{2}$, the family by light regimen interaction variance and $\left(\sigma_{1}-\sigma_{2}\right)^{2}$, which represents the change in the family variance component across the two light regimens.

Analysis of variance also provided statistics for the calculation of $r_{\mathrm{G}}$ without confounding effects of within-family (co)variance. We used Yamada's (1962) method for estimating the genetic correlation of the same character under different environments:

$r_{\mathrm{G}}=\sigma_{\mathrm{G}}^{2} /\left(\sigma_{\mathrm{G}}^{2}+\sigma_{\mathrm{GE}}^{2}\right)$,

where $\sigma_{\mathrm{G}}^{2}$ and $\sigma_{\mathrm{GE}}^{2}$ refer to the family and genotype by environment interaction variance, respectively. This relationship was orginally formulated for a random two-way ANOVA but corresponds to the $F$-ratio $\mathrm{MS}_{\mathrm{G}} /$ $\mathrm{MS}_{\mathrm{GE}}$ in the mixed-model ANOVA, where $\mathrm{MS}_{\mathrm{G}}$ is the family mean square and $\mathrm{MS}_{\mathrm{GE}}$ is the interaction mean square. As suggested by Fry (1992), who noted that the variance component due to family means in the SAS version of the mixed-model ANOVA (model II in Hocking, $1973)$, this $F$-ratio can be used to test whether $r_{\mathrm{G}}$ differs from zero, provided that data are balanced and family variances are equal in different environments. In the present study, data were slightly unbalanced, so the F-tests are likely to be approximate. The assumption that the covariance of family means is the same for every pair of environments, as required by the saS model (Ayres \& Thomas, 1990), is automatically satisfied when there are only two environments. To adjust for unequal family mean variances, which bias the absolute value of $r_{\mathrm{G}}$ downward (Yamada, 1962), we determined $r_{\mathrm{G}}$ by replacing the denominator of eqn 2 with $\sigma_{1} \sigma_{2}$ (Via, 1984b; Fry 1992). Following the subtraction of the block mean from each observation (when the block effect was significant), we also calculated the family-mean correlations across the light regimens, bearing in mind that these estimates include fractions of the sampling variance within families (Via, 1984b).

Finally, we used the $F_{3}$ plants to explore the relationship between total flower number and each of the continuous characters to see whether the observed value of $r_{G}$ would translate into genetic tradeoffs preventing the experimental population from evolving an appropriate level of response to both light environments. Total flower number was estimated as the product of head number and flower number per head and provided a rough measure of (reproductive) fitness. Product-moment correlation coefficients were calculated to quantify the overall relationship between each trait and fitness, whereas the multiple regression approach of Lande \& Arnold (1983) was used to estimate the direct effect of a character on fitness, with all other variables held constant.

\section{Results}

\section{Parent generation}

With the exception of three individuals under the shade cloth, the outcrop plants always produced anthocyanin leaf spots whereas all the weed plants lacked leaf spots in both light regimens. Analysis of variance revealed a significant effect of population for all the continuously distributed characters (Table 2) with the outcrop plants having a larger number of shorter, relatively narrower and more deeply lobed leaves, later flowering, a shorter stem with shorter branches and a larger number of smaller heads than those originating from the weed site (Fig. 1). These differences were apparent in both light regimens, except that the separation of the populations was significantly greater in shade for leaf dissection and plant height, and in full sunshine for relative leaf width and head width (Fig. 1, Table 2). Overall, shaded plants had longer, narrower and less-lobed leaves, a taller stem with longer branches, fewer flower heads and a smaller number of flowers per head than plants raised in full sunshine.

\section{Hybrid generations}

The frequency of anthocyanic plants differed greatly among families in the $\mathrm{F}_{3}$ and $\mathrm{F}_{4}$ generations $(P<0.001)$ 
Table $2 F$-values computed from three-way ANOVA of data obtained for the parent generation

\begin{tabular}{|c|c|c|c|c|}
\hline Character & Block & Population & Environment & $\begin{array}{l}\text { Population } \times \\
\text { environment }\end{array}$ \\
\hline Leaf length & 0.57 n.s. & $4.39^{*}$ & $35.00^{* * *}$ & 3.19 n.s. \\
\hline Leaf dissection & 1.26 n.s. & $185.48^{* * * *}$ & $23.25^{* * *}$ & $20.70^{* * * *}$ \\
\hline Relative leaf width & 1.17 n.s. & $28.89^{* * * *}$ & $14.48^{* * * * *}$ & $7.18^{* *}$ \\
\hline Leaf number & 0.86 n.s. & $1693.42^{* * *}$ & 3.40 n.s. & $5.49^{*}$ \\
\hline Flowering date & 1.81 n.s. & $456.61^{* * *}$ & 2.39 n.s. & 0.07 n.s. \\
\hline Plant height & 1.60 n.s. & $1427.76^{* * *}$ & $42.25^{* * * *}$ & $21.17^{* * * *}$ \\
\hline Branch length & 1.37 n.s. & $223.54 * * *$ & $11.28^{* *}$ & 0.04 n.s. \\
\hline Head width & 0.67 n.s. & $959.77 * * *$ & 2.43 n.s. & $21.78^{* * * *}$ \\
\hline Seed length & 1.20 n.s. & $15.18^{* * * *}$ & 0.64 n.s. & 2.37 n.s. \\
\hline Heads/plant & 0.72 n.s. & $10.17^{* *}$ & $14.55^{* * * *}$ & 0.87 n.s. \\
\hline Flowers/head & $2.78^{*}$ & $61.16^{* * *}$ & $7.62 * *$ & 3.31 n.s. \\
\hline
\end{tabular}

*** $P<0.001,{ }^{* *} P<0.01,{ }^{*} P<0.05$, n.s. not significant $(P>0.05)$.

and was higher in the sun treatment than in the shade treatment, both in the $\mathrm{F}_{3}$ generation ( 38 vs. 19 per cent, $P<0.001)$ and in the $\mathrm{F}_{4}$ generation $(36$ vs. 25 per cent, $P=0.002$ ). There was no significant interaction between family, light regimen and anthocyanin pigmentation $(P>0.50)$, showing that the families responded similarly to a drastic reduction in light intensity.

The main effect of family was significant for all continuous traits, the only exception being $F_{3}$ leaf length (Table 3), with family means spanning the whole range between the parent means (Fig. 1). For leaf length, relative leaf width, total head number, flower number per head and seed length, the between-family variation in the $F_{3}$ exceeded the parental means, especially in shade. Transgressive segregation was also observed when phenotypic values were considered but only for some of the characters (Table 4). As revealed by the $\mathrm{F}$ values (Table 3 ), the effect of growing the plants in different light regimens was usually greater than the effect of family, with environmental changes being in the same direction as in the parent generation; shade responses confined to the segregating generations include a slight decrease in head width and seed length $\left(\mathrm{F}_{3}\right.$; Fig. 1). Judging from the significant interaction terms (Table 3), the families had non-parallel responses in leaf length, leaf dissection, leaf number, flowering date, plant height and total head number. In two cases, the family by environment interaction accounted for a greater fraction of the variance than the average effect of family $\left(\mathrm{F}_{3}\right.$ leaf length and head number; Table 5). For characters with a statistically significant interaction term (Table 3 ), changes in the family variances between light regimens explained a greater proportion of the interaction variance than changes in the rank of families, with the notable exception of leaf length and (to a lesser extent) leaf dissection (Table 5).

\section{Across-environment correlations}

All estimates of $r_{\mathrm{G}}$ were positive and most values approached one (Table 6), showing that most families retained their ranks across light regimens. As expected from the large variance component arising from shifts in the genotypic ranking between environments (Table $5)$, leaf length had the smallest value of $r_{\mathrm{G}}$ in both the $F_{3}$ and $F_{4}$ generations. The family-mean correlations, calculated on data corrected for block differences, differed significantly from zero in most cases but were of lower magnitude than those calculated by Yamada's (1962) method, especially when adjusted for unequal family variances.

\section{Phenotypic selection}

The selection coefficients differed greatly in their magnitude depending on the character and method of estimation (Table 7). According to the correlation analysis, total flower number (fitness) increased with leaf length, degree of leaf dissection, leaf number and flowering date but was negatively related to relative leaf width and head width. There was no shift between light regimens in the sign of the correlation but the estimates were generally larger for plants grown in shade than for plants exposed to full sunshine. The large positive influence of large leaves on fitness was also apparent when direct forces of selection were considered (multiple regression) but no effect of flowering 

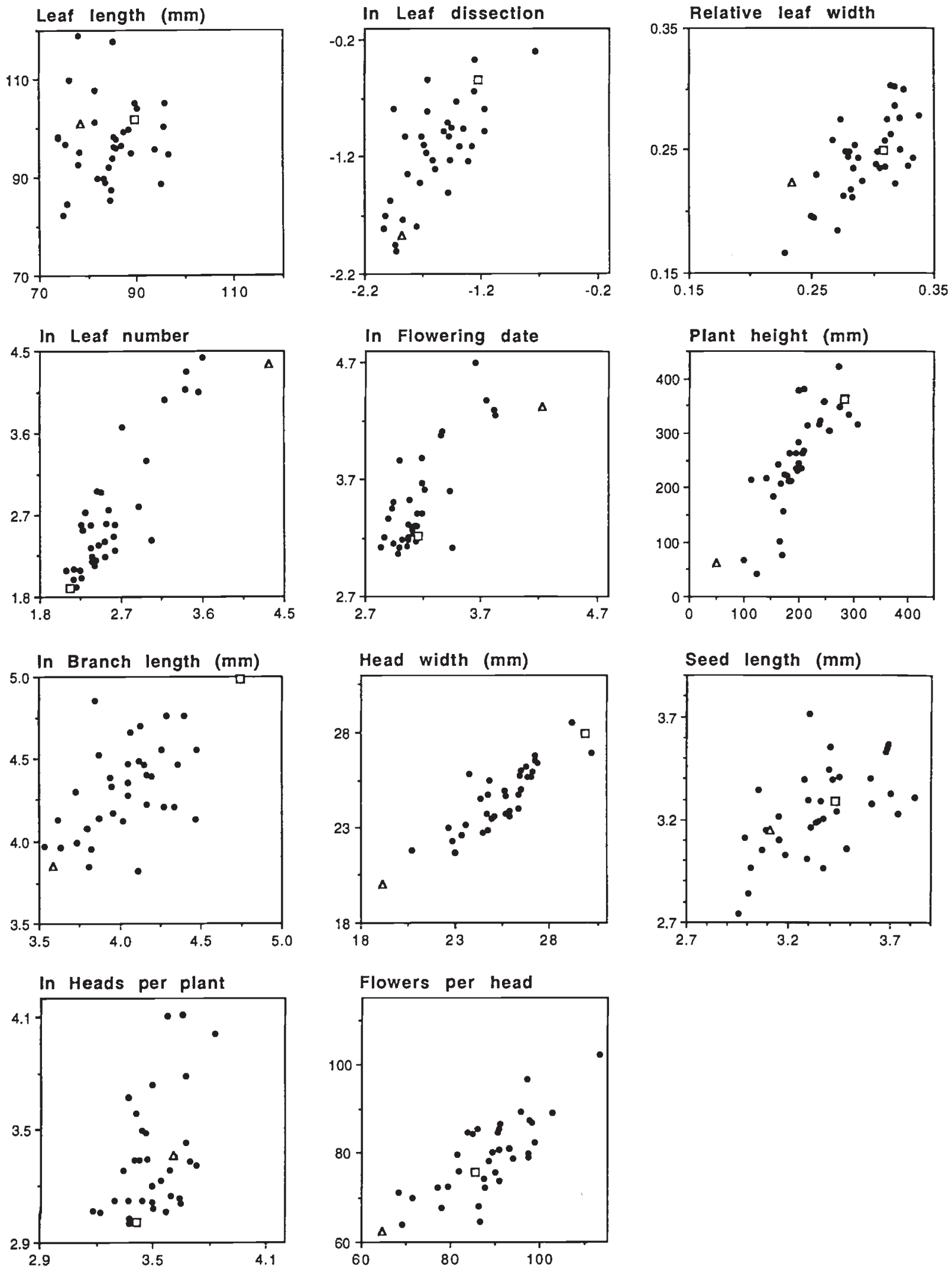

Fig. 1 Norms of reaction for selfed $F_{3}$ families raised in full sunlight ( $x$-axis) and shade ( $y$-axis). Families with identical mean values in the two light regimens would fall on the diagonal. The parental values (least-square means) are shown with triangle (outcrop) and square (weed). 


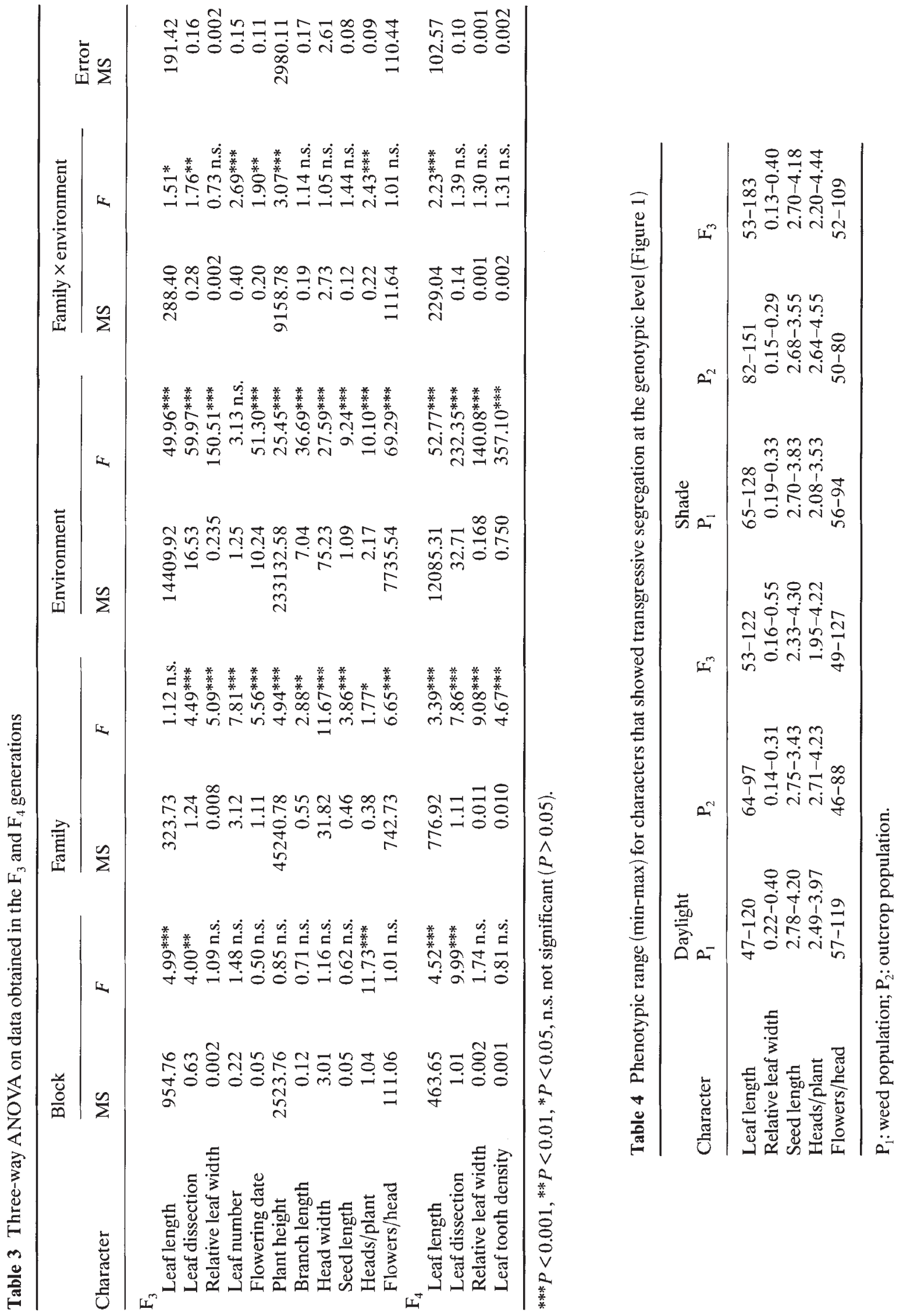


Table 5 Components of variance for characters measured in the $F_{3}$ and $F_{4}$ generations

\begin{tabular}{|c|c|c|c|c|c|c|}
\hline \multirow[b]{2}{*}{ Character } & \multicolumn{2}{|c|}{ Factorial ANOVA } & \multicolumn{2}{|c|}{ One-way ANOVA } & \multicolumn{2}{|c|}{ Partitioning of $V_{\text {famxE }}$} \\
\hline & $V_{\text {fam }}$ & $V_{\text {famxE }}$ & $V_{\text {sun }}$ & $V_{\text {shade }}$ & $V_{\text {var }}$ & $V_{\text {rank }}$ \\
\hline \multicolumn{7}{|l|}{$\mathrm{F}_{3}$} \\
\hline Leaf length & 3.2028 & 17.5901 & 19.4476 & 18.2180 & 0.0100 & 17.5800 \\
\hline Leaf dissection & 0.0872 & 0.0215 & 0.0681 & 0.1465 & 0.0074 & 0.0141 \\
\hline Flowering date & 0.0825 & 0.0171 & 0.0505 & 0.1468 & 0.0126 & 0.0046 \\
\hline Plant height & 3280.2335 & 1123.3124 & 1959.0024 & 6509.2483 & 663.1825 & 460.1299 \\
\hline Branch length & 0.0327 & 0.0043 & 0.0426 & 0.0281 & 0.0008 & 0.0035 \\
\hline Head width & 2.6436 & 0.0216 & 3.1990 & 2.1317 & 0.0540 & -0.0323 \\
\hline Seed length & 0.0310 & 0.0066 & 0.0486 & 0.0249 & 0.0020 & 0.0047 \\
\hline Leaf dissection & 0.0817 & 0.0066 & 0.0872 & 0.0913 & 0.0000 & 0.0066 \\
\hline Relative leaf width & 0.000820 & 0.000047 & 0.000964 & 0.000793 & 0.000004 & 0.000043 \\
\hline Leaf tooth density & 0.000651 & 0.000085 & 0.000704 & 0.000775 & 0.000001 & 0.000084 \\
\hline
\end{tabular}

$V_{\text {fam }}$ is the among-family variance across light regimens, $V_{\text {famxE }}$ the family by environment interaction variance, $V_{\text {sun }}$ and $V_{\text {shade }}$ the among-family variance in full sunshine and shade, respectively, $V_{\text {var }}$ the interaction variance due to changes in the amongfamily variance across light regimens, and $V_{\text {rank }}$ the interaction variance due to shifts in the ranking of genotypes in the two environments.

Table 6 Genetic correlations across light regimens

\begin{tabular}{llll}
\hline Character & $r_{\mathrm{G} 1}$ & $r_{\mathrm{G} 2}$ & $r_{\mathrm{G} 3}$ \\
\hline $\mathrm{F}_{3}$ Leaf length & & & \\
$\quad$ Leaf dissection & 0.15 & 0.17 & 0.06 n.s. \\
$\quad$ Leaf width/length & 1.22 & 0.87 & $0.70^{* * * *}$ \\
Leaf number & 0.84 & 0.97 & $0.68^{* * *}$ \\
Flowering date & 0.83 & 0.96 & $0.88^{* * *}$ \\
Plant height & 0.75 & 0.92 & $0.78^{* * *}$ \\
Branch length & 0.88 & 0.95 & $0.47^{* * *}$ \\
Head width & 0.99 & 1.01 & $0.84^{* * *}$ \\
Seed length & 0.82 & 0.89 & $0.59^{* * *}$ \\
Heads/plant & 0.40 & 0.60 & $0.43^{*}$ \\
Flowers/head & 1.00 & 1.06 & $0.75^{* * * *}$ \\
F $_{4}$ & & & \\
Leaf length & 0.68 & 0.72 & $0.58^{* * * *}$ \\
Leaf dissection & 0.93 & 0.92 & $0.78^{* * *}$ \\
Leaf width/length & 0.95 & 0.94 & $0.80^{* * *}$ \\
Leaf tooth density & 0.89 & 0.88 & $0.64^{* * * *}$ \\
\hline
\end{tabular}

$r_{\mathrm{G} 1}$ and $r_{\mathrm{G} 2}$ are component correlations calculated according to Yamada (1962), with $r_{\mathrm{G} 2}$ corrected for changes in the among-family variance across environments. $r_{\mathrm{G} 3}$ is the family-mean correlation (data adjusted for block differences).

All correlations for a given character were significant at the same level. ${ }^{* * *} P<0.001,{ }^{* *} P<0.01,{ }^{*} P<0.05$, n.s. not significant $(P>0.05)$. date and head width on fitness was found after adjusting for variation in other characters. In some cases, the regression coefficient differed greatly in magnitude between the two light regimens although the large number of variables in the analysis reduced the power to detect most of these differences as statistically significant. A weakly significant result involves a tendency for leaf number to have a stronger impact on fitness in shade than in full sunshine.

\section{Discussion}

\section{Ecotypic differentiation vs. phenotypic plasticity}

Numerous characters have been subject to genetic differentiation in Crepis tectorum, particularly in regions where the widespread weed type grades into forms adapted to rock outcrops (Andersson, 1990, $1991,1993)$ but there is also evidence that the most distinctive traits display considerable plasticity (Andersson, 1989a, b), raising the question why local differentiation rather than wide phenotypic plasticity has been favoured as the predominant adaptive strategy in this species. In the present study, we evaluate the hypothesis that the genetic correlation structure is more conducive to local genetic differentiation than to the evolution of plastic genotypes 
Table 7 Relationship between each character and fitness (no. of flowers per plant) in the two light regimens, as determined by the Pearson correlation coefficient and the partial regression coefficient

\begin{tabular}{|c|c|c|c|c|c|c|}
\hline \multirow[b]{2}{*}{ Character } & \multicolumn{3}{|l|}{ Correlation } & \multicolumn{3}{|c|}{ Multiple regression } \\
\hline & Sun & Shade & Test & Sun & Shade & Test \\
\hline Leaf length & $0.40^{* * *}$ & $0.45^{* * *}$ & n.s. & $0.53^{* * * *}$ & $0.33^{* * *}$ & n.s. \\
\hline Leaf dissection & $-0.19^{* *}$ & $-0.53^{* * *}$ & $* * *$ & -0.06 n.s. & $-0.14^{*}$ & n.s. \\
\hline Leaf width/length & 0.02 n.s. & $-0.25^{* * *}$ & $* *$ & - & - & - \\
\hline Leaf number & $0.29^{* * *}$ & $0.69^{* * *}$ & $* * *$ & 0.16 n.s. & $0.59^{* * *}$ & * \\
\hline Flowering date & $0.22^{* * *}$ & $0.62^{* * *}$ & $* * *$ & $0.14 \mathrm{n} . \mathrm{s}$ & -0.10 n.s. & n.s. \\
\hline Plant height & -0.10 n.s. & $-0.36^{* * *}$ & $* *$ & -0.10 n.s. & -0.12 n.s. & n.s. \\
\hline Branch length & -0.09 n.s. & -0.11 n.s. & n.s. & -0.13 n.s. & $-0.12^{*}$ & n.s. \\
\hline Head width & $-0.21^{* *}$ & $-0.37^{* * *}$ & n.s. & -0.07 n.s. & 0.06 n.s. & n.s. \\
\hline Seed length & -0.12 n.s. & -0.11 n.s. & n.s. & -0.08 n.s. & $-0.12^{*}$ & n.s. \\
\hline Sample size & 199 & 172 & & 199 & 172 & \\
\hline
\end{tabular}

Leaf width/length was excluded from the regression analyses (the denominator being entered as a separate variable).

Test refers to a statistical comparison of correlations ( $t$-test of z-transformed values) and regression coefficients (test of the environment by trait interaction in ANCOVA). ${ }^{* * *} P<0.001,{ }^{* *} P<0.01,{ }^{*} P<0.05$, n.s. not significant $(P>0.05)$.

capable of attaining the optimum phenotype in every habitat.

Genetic correlations between character states expressed in different environments can limit the potential for reaction norm evolution if there is spatial heterogeneity in selection pressures and extensive gene flow between sites with different selection regimens (Via \& Lande, 1985). Therefore, in the remainder of this discussion, it is necessary to assume that many seeds germinate in sites that are markedly different from the sites of the parent plants, a likely scenario in the wind-dispersed Crepis tectorum considering the wide range of habitats occupied by the species (Babcock, 1947), the great colonizing ability of the weed ecotype (e.g. Najda et al., 1982) and the sharp environmental gradients characterizing many outcrop sites (Andersson, 1992).

When inbred $\mathrm{F}_{3}$ and $\mathrm{F}_{4}$ families were grown across a steep light gradient, changes in the magnitude of the genotypic variances generally accounted for a larger proportion of the interaction variance than the shifts in the genotypic ranks, with values of $r_{\mathrm{G}}$ approaching unity for most traits, particularly when estimated by Yamada's (1962) method and when adjusted for changes in the family variance. The greatest departure of $r_{\mathrm{G}}$ from one was found for leaf length just prior to flowering $\left(\mathrm{F}_{3}\right)$, indicating near-independence of the genotypic value in the two light regimens for at least one character. While different estimates of $r_{\mathrm{G}}$ were in good qualitative agreement on a trait by trait basis, we note that the family-mean correlations were of lower magnitude than those based on genetic components of variance (Yamada, 1962; Fry, 1992), presumably because of sampling variance within families (Via, 1984b).

Our finding that genotypes retain their relative ranking despite a large reduction in light intensity shows that a similar set of genes determines the character states across a steep environmental gradient (Falconer, 1952). Such pleiotropic effects can limit the independent evolution of character states expressed in different light regimens but whether adaptive changes in the reaction norm are facilitated or retarded depends on the mode of selection in each environment (Via \& Lande, 1985). As for major components of fecundity like the number of inflorescences and the number of flowers per inflorescence, one would expect selection to favour the same genotypes in the two light regimens, thereby enhancing the fixation of alleles with positive effects on overall performance. Hence, to the extent that flower production is strongly correlated with lifetime fitness, there is thus no support for the idea that adaptation to full sunlight would sacrifice adaptation to shady conditions, extending similar findings of other recent studies (Via, 1984b; Shaw, 1986; Futuyma \& Moreno, 1988; Bennett et al., 1990; Miller \& Schemske, 1990; Platenkamp \& Shaw, 1992; Shaw \& Platenkamp, 1993; but see Fry, 1990; Via, 1991). Some caution must be exercised in the interpretation of genetic correlations based on full-sib families 
(Falconer, 1981), particularly in the present investigation which indicates a non-additive genetic effect on traits related to flower production (see below). Moreover, inbreeding or the use of novel greenhouse conditions (e.g. Rose, 1984; Service \& Rose, 1985) may result in fitness variation being positively correlated across environments thus hiding existing tradeoffs (Fry, 1993).

To detect genetic tradeoffs within the reaction norm for characters not directly connected with fitness, it is necessary to assess the relationship between each trait and fitness across environments (Via \& Lande, 1985). Without measurements of selection in the field (Lande \& Arnold, 1983), comparative data may be useful to infer changes in the phenotypic optimum between sites occupied by the same species: habitat-correlated variation not only provides evidence that genetic differentiation has been more important than plasticity in the adaptation to spatially varying selection but also suggests little opportunity for adaptive plasticity to evolve when character states are strongly positively correlated across environments (Via \& Lande, 1985; Platenkamp \& Shaw, 1992).

Intraspecific variation in Crepis tectorum strongly implies that the optimum phenotype differs between sites, with the most extreme outcrop sites selecting for early-flowering plants with deeply lobed and anthocyanic leaves, decumbent growth and small seeds and the less extreme outcrop and weed habitats favouring the opposite combination of characters. Interpopulation variation in leaf traits, flowering phenology and plant architecture is related to different levels of abiotic stress (insolation, wind exposure, drought, nutrient deficiency) and the potentially high levels of competition encountered by plants in the most fertile and mesic habitats, e.g. arable fields (Andersson, 1989a, b) whereas the size of the attractive structures (head width) appears to reflect the 'openness' of the habitat (and the potential for cross-pollination) within each of these categories (Andersson, 1989c).

Indirect evidence of disruptive selection across sites with different levels of shade coupled with the observation of nearly parallel reaction norms for ecologically relevant characters indicate a limited potential for phenotypes expressed in each light regimen to evolve directly to their individual optima. However, although it may be difficult for adaptive plasticity to evolve in the face of environmental variability under these conditions, further studies are required to examine whether this conclusion holds for environmental variables other than light intensity.

Any adaptive change in the character mean in one environment will be accomplished by a correlated change of the mean in the second environment if the two character states are genetically correlated (Falconer, 1952; Via \& Lande, 1985). Accordingly, there should be a potential for selection responses in one habitat to carry over to parts of the reaction norm never expressed in that habitat. Such non-adaptive changes in the reaction norm could account for the similarity between large-scale patterns of variation detected on the basis of field-collected plants (Andersson, 1990) and those revealed when plants from geographically distant populations are grown under unnatural glasshouse conditions (e.g. Andersson, 1993).

\section{Population differentiation in phenotypic plasticity}

Genetic tradeoffs within the reaction norm do not necessarily imply long-term constraints on the evolution of adaptive plasticity. As shown in the present study, light-grown plants of Crepis tectorum differ from those raised in shade in having shorter stems, wider flower heads and leaves with a more subdivided surface and a greater propensity to produce anthocyanin spots. These changes parallel the geneticallybased differences between populations occupying the driest and most exposed outcrop sites and those in more mesic and closed habitats (see above) and may thus represent adaptive responses to small-scale environmental heterogeneity within sites, thereby supporting the idea that populations eventually evolve towards the appropriate character states (Via \& Lande, 1985). An alternative interpretation of similarities in genetic and plastic responses is that environmental modifications have become genetically assimilated at the among-population level (Waddington, 1959; Andersson, 1989a).

The lack of crossing reaction norms across the light gradient does not exclude the possibility that such interactions exist for other environmental variables. Previous work on Crepis tectorum has demonstrated heritable variation in the response to germination time: outcrop plants flower 2 or 3 weeks earlier than plants of the weed ecotype when seed germination occurs in the previous autumn whereas the difference is reversed for plants that emerge and flower in the same year (this study; Andersson, 1989b). Also, even though strong cross-environment correlations were the most predominant feature in this study, our results also indicate consistent differences among genotypes in the magnitude of response: changes in the family-mean variance accounted for a substantial part of the family by environment interaction and the separation of the parental means differed significantly between the light regimens for several traits. These observations are in agreement with the population divergence in morphological plasticity seen in a prior study of Crepis 
tectorum (Andersson, 1989a) and complement the work of Khan et al. (1976), who reported genetic segregation for the plastic response to plant density in crosses between two varieties of Linum usitatissimum. When combined with the numerous studies demonstrating within-population variation in plasticity in a wide range of other organisms (e.g. Westerman, 1970; Gupta \& Lewontin, 1982; Via, 1984a; Shaw, 1986; Trexler \& Travis, 1990; Weis \& Gorman, 1990; Mazer \& Schick, 1991; Via, 1991; Schmitt et al., 1992), available data clearly suggest a potential for phenotypic plasticity to evolve by natural selection (or genetic drift).

Our results provide no evidence for population differences in the reaction norm for leaf length and flowering date, yet these traits showed highly significant genotype by environment interactions in the hybrid generations. Together with the presence of transgressive segregants that exceeded the parental values within light regimens, these observations lead to the suggestion that a relatively similar trait expression may be influenced by different genes in the two populations (Khan et al., 1976) or that parental genes interacted non-additively in the hybrid generations (Mather \& Jinks, 1982). Mechanisms that could explain why the interaction terms for relative leaf width and head width were significant in the parent generation but not in the $\mathrm{F}_{3}$ generation are not readily apparent.

Genetically-based tradeoffs within the reaction norm are just one of several factors that might prevent a population from evolving the optimum phenotypic response across an environmental gradient. Aside from various costs associated with being a plastic generalist (van Tienderen, 1991), it has been suggested that developmental constraints place an upper limit on the range of phenotypes that can be expressed in a character (Stebbins, 1950). For example, in a recent experiment in which weed and outcrop populations of Crepis tectorum were replicated in a number of garden and glasshouse environments (Andersson, 1989a), there was a striking similarity between populations in the rank of characters with respect to their plasticity despite considerable population divergence in the overall mean, implying evolutionary stability in the amount of response. Trait-specific plasticity may be a manifestation of the length of time during which the meristems are active or the amount of cell elongation that takes place during the growth of the organ (Stebbins, 1950).

\section{Prediction of reaction norm evolution in an artificial environment}

In an attempt to predict how the (average) reaction norm would evolve in an artificial habitat with small- scale spatial variability in light intensity, we carried out a selection analysis using the total flower number as a measure of reproductive fitness. According to the correlation analysis which allowed 'early' characters like flowering time and the leaf variables to influence total flower number through 'late' characters (plant architecture and floral variables), our results demonstrated a selective advantage of late flowering and a large number of narrow and dissected leaves irrespective of light intensity; selection was stronger in the shady patches than in the exposed ones but there was no shift in the direction of selection across light regimens. Similar results were obtained when multiple regression was used to control for variation in other characters, providing confidence in the overall pattern.

Assuming that zygotes are distributed at random across light regimens and leaving aside the various problems associated with these analyses (artificial environments, no mortality selection, transient linkage disequilibrium due to hybridization, etc), one would expect a genetic change in the elevation of the reaction norm for flowering date and some of the leaf variables, with some of the response in the sunny patches being an indirect response to the stronger selection pressures imposed by the shade environment. A similar prediction holds for leaf length but in this case it would be unnecessary to invoke correlated genetic responses as selection was strong in both light regimens.

\section{Acknowledgements}

During the course of this study, S.A. was supported by the Swedish Natural Research Council (postdoctoral fellowship). Greenhouse facilities were provided by the University of California (Riverside). Technical assistance by Larry Summers is also acknowledged.

\section{References}

Andersson, s. 1989a. Phenotypic plasticity in Crepis tectorum (Asteraceae). Pl. Syst. Evol., 168, 19-38.

ANDERsSON, S. 1989b. Life-history evolution in Crepis tectorum (Asteraceae). Oecologia (Berl.), 80, 540-545.

ANDERSSON, s. 1989c. The evolution of self-fertility in Crepis tectorum (Asteraceae). Pl. Syst. Evol., 168, 227-236.

ANDERSSON, S. 1990. A phenetic study of Crepis tectorum in Fennoscandia and Estonia. Nord. J. Bot., 9, 589-600.

ANDERSSON, S. 1991. Geographical variation and genetic analysis of leaf shape in Crepis tectorum (Asteraceae). Pl. Syst. Evol., 178, 247-258.

ANDERSSON, S. 1992. Phenotypic selection in a population of Crepis tectorum ssp. pumila. Can. J. Bot., 70, 89-95.

ANDERSSON, s. 1993. Morphometric differentiation, patterns of interfertility and the genetic basis of character evolution in Crepis tectorum (Asteraceae). Pl. Syst. Evol., 184, $27-40$. 
AYRES, M. P. AND THOMAS, D. L. 1990. Alternative formulations of the mixed-model ANOva applied to quantitative genetics. Evolution, 44, 221-226.

BABCOCK, E. B. 1947. The genus Crepis I-II. University of California Press, Berkeley, CA.

BENNETT, A. F., DAO, K. M. AND LENSKI, R. E. 1990. Rapid evolution in response to high-temperature selection. Nature, 346, 79-81.

BJÖRKMAN, O. AND HOLMGREN, P. 1963. Adaptability of the photosynthetic apparatus to light intensity in ecotypes from exposed and shaded habitats. Physiol. Plant., 16, 889-914.

BRADSHAW, A. D. 1965. Evolutionary significance of phenotypic plasticity in plants. Adv. Genet., 13, 115-155.

BULmer, M. 1985. Mathematical Quantitative Genetics, Clarendon Press, Oxford.

CONOVER, D. O., VAN voorheES, D. A. AND EHTisham, A. 1992. Sex ratio selection and the evolution of environmental sex determination in laboratory populations of Menidia menidia. Evolution, 46, 1722-1730.

COOK, S. A. AND JOHNSON, M. P. 1968. Adaptation to heterogeneous environments. I. Variation in heterophylly in Ranunculus flammula L. Evolution, 22, 496-516.

FALCONER, D. S. 1952. The problem of environment and selection. Am. Nat., 86, 293-298.

FALCONER, D. S. 1981. Introduction to Quantitative Genetics, 2nd edn. Longman, London.

FALCONER, D. S. 1990. Selection in different environments: effects on environmental sensitivity (reaction norm) and on mean performance. Genet. Res., 56, 57-70.

FRY, J. D. 1990. Tradeoffs in fitness on different hosts: evidence from a selection experiment with a phytophagous mite. Am. Nat., 136, 569-580.

FRY, J. D. 1992. The mixed-model analysis of variance applied to quantitative genetics: biological meaning of the parameters. Evolution, 46, 540-550.

FRY, J. D. 1993. The 'general vigor' problem; can antagonistic pleiotropy be detected when genetic covariances are positive? Evolution, 47, 327-333.

FUTUYMA, D. J. AND MORENO, G. 1988. The evolution of ecological specialization. Ann. Rev. Ecol. Syst., 19, 207-233.

GABRIEL, W. AND LYNCH, M. 1992. The selective advantage of reaction norms for environmental tolerance. J. Evol. Biol., $\mathbf{5}, 41-59$

GOMULKIEWICZ, R. AND KIRKPATRICK, M. 1992. Quantitative genetics and the evolution of reaction norms. Evolution, 46, 390-411.

GUPTA, A. P. AND LEWONTIN, R. C. 1982. A study of reaction norms in natural populations of Drosophila pseudoobscura. Evolution, 36, 934-948.

HICKMAN, J. C. 1975. Environmental unpredictability and plastic energy allocation strategies in the annual Polygonum cascadense (Polygonaceae). J. Ecol., 63, 689-701.

HOCKING, R. R. 1973. A discussion of the two-way mixed model. Am. Statist., 27, 148-152.

KHAN, M. AKRAM AND BRADSHAW, A. D. 1976. Adaptation to heterogeneous environments. II. Phenotypic plasticity in response to spacing in Linum. Aust. J. Agric. Res., 27, 519-531.
KHAN, M. AKRAM, ANTONOVICS, J. AND BRADSHAW, A. D. 1976. Adaptation to heterogeneous environments. III. The inheritance of response to spacing in Flax and Linseed (Linum usitatissimum). Aust. J. Agric. Res., 27, 649-659.

LACEY, E. P., REAL, L., ANTONOVICS, J. AND HECKEL, D. G. 1983. Variance models in the study of life histories. Am. Nat., 122, 114-131.

LANDE, R. AND ARNOLD, S. J. 1983. The measurement of selection on correlated characters. Evolution, 37, 1210-1226.

MATHER, K. AND JINKS, J. L. 1982. Biometrical Genetics, 3rd edn. Chapman and Hall, London.

MAZER, S. J. AND SCHICK, C. T. 1991. Constancy of population parameters for life history and floral traits in Raphanus sativus L. I. Norms of reaction and the nature of genotype by environment interactions. Heredity, 67, 143-156.

MILLER, T. E. AND SCHEMSKE, D. W. 1990. An experimental study of competitive performance in Brassica rapa (Cruciferae). Am. J. Bot., 77, 993-998.

MOONEY, H. A. 1980. Photosynthetic plasticity of populations of Heliotropium curassavicum $\mathrm{L}$. originating from differing thermal regimes. Oecologia (Berl.), 45, 372-376.

NAJDA, H. G., DARWENT, A. L. AND HAMILTON, G. 1982. The biology of Canadian weeds 54. Crepis tectorum. Can. J. Plant. Sci., 62, 473-481.

NEWMAN, R. A. 1988. Adaptive plasticity in development of Scaphiopus couchii tadpoles in desert ponds. Evolution, 42, 774-783.

PlatenkAmp, G. A. J. AND SHAW, R. G. 1992. Environmental and genetic constraints on adaptive population differentiation in Anthoxanthum odoratum. Evolution, 46, 341-352.

ROBERTSON, A. 1959. The sampling variance of the genetic correlation coefficient. Biometrics, 15, 469-485.

Rose, M. R. 1984. Genetic covariation in Drosophila life history: Untangling the data. Am. Nat., 123, 565-569.

SAS, 1985. SAS Users Guide: Statistics. SAS Institute Inc., Cary, NC, USA.

SCHEINER, S. M. AND LYMAN, R. F. 1989a. The genetics of phenotypic plasticity. I. Heritability. J. Evol. Biol., 2, 95-107.

SCHEINER, S. M. AND LYMAN, R. F. 1989b. The genetics of phenotypic plasticity. II. Response to selection. J. Evol. Biol., 3, 23-50.

SCHLichting, C. D. 1986. The evolution of phenotypic plasticity in plants. Ann. Rev. Ecol. Syst., 17, 667-693.

SCHLICHTING, C. D. AND LEVIN, D. A. 1990. Phenotypic plasticity in Phlox. III. Variation among natural population of $P$. drummondii. J. Evol. Biol., 3, 411-428.

SCHMAlhausen, I. I. 1949. Factors of Evolution. Blakeston, PA, USA.

SCHMITT, J., NILES, J. AND WULFF, R. D. 1992. Norms of reaction of seed traits to maternal environments in Plantago lanceolata. Am. Nat., 139, 451-466.

SERVICE, P. M. AND ROSE, M. R. 1985. Genetic covariation among life-history components: the effect of novel environments. Evolution, 39, 943-945.

SHAW, R. G. 1986. Response to density in a wild population of the perennial herb Salvia lyrata: variation among families. Evolution, 40, 492-505.

SHAW, R. G. AND PLATENK AMP, G. A. J. 1993. Quantitative genetics of competitive ability in Nemophila menziesii. Evolution $47,801-812$. 
STEARNS, S. C. 1989. The evolutionary significance of phenotypic plasticity. Bioscience, 39, 436-445.

STEBBINS, G. L. 1950. Variation and Evolution in Plants. Columbia, New York.

SULTAN, S. E. 1987. Evolutionary implications of phenotypic plasticity in plants. Evol. Biol., 21, 127-178.

TREXLER, J. C. AND TRAVIS, J. 1990. Phenotypic plasticity in the sailfin molly, Poecilia latipinna (Pisces: Poeciliidae). I. Field experiments. Evolution, 44, 143-156.

VAN TIENDEREN, P. H. 1991. Evolution of generalists and specialists in spatially heterogeneous environments. Evolution, 45, 1317-1331.

VIA, s. 1984a. The quantitative genetics of polyphagy in an insect herbivore. I. Genotype-environment interaction in larval performance on different host plant species. Evolution, 38, 881-895.

VIA, S. 1984b. The quantitative genetics of polyphagy in an insect herbivore. II. Genetic correlations in larval performance within and among host plants. Evolution, 38, 896-905.
VIA, S. 1991. The genetic structure of host plant adaptation in a spatial patchwork: demographic variability among reciprocally transplanted pea aphid clones. Evolution, 45, 827-852.

VIA, S. AND LANDE, R. 1985. Genotype-environment interaction and the evolution of phenotypic plasticity. Evolution, 39, 505-522.

WADDINGTON, C. H. 1959. Canalization of development and genetic assimilation of acquired characters. Nature, 183, $1654-1655$.

WEIS, A. E. AND GORMAN, w. L. 1990. Measuring selection on reaction norms: an exploration of the Eurosta-Solidago system. Evolution, 44, 820-831.

WESTERMAN, J. M. 1970. Genotype-environment interaction and developmental regulation in Arabidopsis thaliana. IV. Wild material: analysis. Heredity, 26, 383-395.

YAMADA, Y. 1962. Genotype by environment interaction and genetic correlation of the same trait under different environments. Jpn J. Genet., 37, 489-509.

ZIMMERMAN, C. A. 1976. Growth characteristics of weediness in Portulaca oleracea. Ecology, 57, 964-974. 